\title{
Caminos de frontera: de la ausencia estatal a la inclusión excluyente de la región Amazónica
}

\author{
Javier Revelo-Rebolledo* \\ University of Pennsylvania (Filadelfia, EE.UU.)
}

Simón Uribe-Martínez (2017). Frontier Road. Power, History, and the Everyday State in the Colombian Amazon. Oxford: Wiley-Blackwell, 279 págs. $^{* *}$

Si bien entre Pasto y Mocoa hay apenas 148 kilómetros, el viaje por carretera aún hoy se demora cinco horas -como mínimo y con suerte-. Hasta hace tres décadas, cuando fue terminada la carretera que conecta a Putumayo con Huila, esa vía era la única forma de entrar a Putumayo. Su trazado es tan peligroso que los habitantes de la región la conocen como "el trampolín de la muerte". Algunos prefieren incluso viajar por el Ecuador para llegar a Nariño. Apoyándose en un estudio histórico, etnográfico y político de esta vía, Simón Uribe Martínez, profesor de la Universidad del Rosario, propone interesantes y agudas reflexiones sobre el papel del Estado en la producción y el mantenimiento de la frontera amazónica. Según el autor, el mal estado de la vía, los conflictos de uso en sus áreas de influencia y los debates relacionados con su origen y cambio, muestran la "exclusión incluyente" de la región amazónica dentro del orden estatal.

El libro de Uribe señala cómo la construcción del llamado "trampolín de la muerte" es a la vez un proyecto de formación del Estado y de constitución de la frontera, en el cual se ha empleado violencia física y simbólica. El Estado colombia-

\footnotetext{
* Magíster y candidato a doctor en Ciencia Política de la Universidad de Pennsylvania (Estados Unidos), politólogo de la Pontificia Universidad Javeriana y abogado de la Universidad Nacional de Colombia. Correo electrónico: jrev@sas. upenn.edu ORCID: https://orcid.org/oooo-ooo3-3122-9839

** Algunas ideas de esta reseña fueron publicadas en Razón Publica (14 de enero de 2018). Recuperado de https://www. razonpublica.com/index.php/lectura/10798-la-construcci\%C3\%B3n-del-putumayo-como-una zona-de-frontera.html
} 
no no está ausente, por el contrario, la región ha sido incorporada al orden estatal de forma violenta (exclusión incluyente). La construcción discursiva de la región como una zona excluida, atrasada, baldía, inculta y sin Estado, entre muchos otros calificativos que ejercen violencia simbólica, ha servido para legitimar una serie de prácticas violentas de inclusión. Para defender esta idea, el estudio se centra en dos momentos históricos claramente definidos: (1) la concepción y construcción de la vía a finales del siglo XIX e inicios del XX, y (2) los debates contemporáneos sobre su uso político y espacial.

La primera parte del libro consta de tres capítulos y analiza el primero de estos momentos: la concepción y la construcción de la vía, que ocurrió entre la segunda mitad del siglo XIX y principios del siglo XX. En esta época la región amazónica (no solo Putumayo) fue concebida como una frontera susceptible de ser apropiada para promover la civilización de los "salvajes", el aprovechamiento de los recursos y la defensa de las fronteras nacionales. Quien mejor articuló esta visión -como empresario, explorador, militar y presidente- fue Rafael Reyes, para quien los proyectos de infraestructura hacían parte de la misión civilizatoria del Estado. Reyes propuso construir el camino en cuestión, que se hizo bajo el liderazgo de los frailes capuchinos. La idea civilizatoria del Estado, que es una forma de violencia simbólica, sirvió para legitimar múltiples actos de violencia física que se ejercieron durante la construcción de la vía: la ruptura de la cordillera con dinamita y la usurpación de las tierras que pertenecían a las comunidades indígenas que además fueron obligadas a trabajar en la vía, entre otros.

Esta sección histórica del libro se basa en la revisión detallada de memorias de viaje y de documentos históricos, algunos de los cuales reposan en archivos históricos de difícil acceso como el de los frailes capuchinos en Sibundoy y Barcelona. Simón Uribe es uno de los pocos investigadores que ha revisado estos archivos después de la publicación del libro de Víctor Daniel Bonilla (1968), Siervos de Diosy amos de indios.

La segunda parte del libro, compuesta por tres capítulos, estudia el segundo momento. Es decir, los conflictos de las últimas décadas asociados con la remodelación de la carretera que consiste en la construcción de una variante al "trampolín de la muerte”, proyecto que hace parte de la Iniciativa para la Integración de la Infraestructura Regional Suramericana (IIRSA). Más etnográfica que histórica, esta sección analiza a profundidad el nuevo megaproyecto y plantea que la violencia simbólica y física persiste y que la condición de frontera se sigue afirmando. También señala los esfuerzos infructuosos del Estado, y en ocasiones contraproducentes, para gobernar las zonas aledañas a la variante. Por ejemplo, el capítulo seis estudia los problemas relacionados con la relocalización de la población en condición de desplazamiento forzado que ocupaba el área de influencia del megaproyecto. 
La tesis de que la configuración de la frontera amazónica es importante para el mantenimiento del orden estatal no es totalmente nueva. El mismo autor lo reconoce al plantear que quien mejor ha articulado esta idea en el contexto colombiano ha sido Margarita Serje en El revés de la nación (2011). El aporte del libro radica, en cambio, en el estudio detallado de las prácticas concretas mediante las cuales se ha configurado la condición de frontera. En lugar de limitarse al estudio de la construcción discursiva de la frontera-es decir, a estudiar las representaciones e imaginarios sobre la región, como lo hace Serje-, Simón Uribe introduce elementos puramente materiales asociados a la construcción y el desarrollo de la vía (p. 11), sin ignorar el papel de los discursos sobre la frontera que han servido para legitimar esas formas violentas y concretas de intervención estatal.

Además de esta contribución teórica, el libro nos ayuda a comprender la complejidad del fenómeno estatal en uno de los departamentos más afectados por el conflicto armado y que en la actualidad es central para la construcción de paz. Sin embargo, el aporte del trabajo no radica en el estudio de las dinámicas del conflicto armado en la región (que se mencionan, pero no son el eje de la narración). La mayoría de estudios académicos sobre Putumayo se han centrado en la coca, la guerrilla, los paramilitares y las causas y consecuencias del conflicto armado (Cancimance, 2017; Centro Nacional de Memoria Histórica, 2011; 2012, 2015; Ramírez, 2001; Torres-Bustamante, 2011). Paradójicamente, el silencio relativo sobre estos temas le permite al autor mostrar que la violencia asociada con la formación de Estado no solo precede las dinámicas contemporáneas del conflicto armado, sino que también las trasciende.

A pesar de sus aportes teóricos, históricos y etnográficos, el trabajo puede ser criticado por no considerar de manera suficiente la diversidad territorial y temporal de la región amazónica. Si bien estudia una región relativamente bien definida, las conclusiones teóricas son mucho más ambiciosas pues además de retratar las particularidades de la vía, plantea que la región amazónica en su conjunto evidencia una lógica política ligada a la configuración de la frontera. Por eso, el objetivo del libro no es contar la historia de la carretera, sino comprender un proceso más amplio de construcción de Estado y frontera: "El significado real de las fronteras, trasciende un contexto espacial, temporal o social específico, y más bien habla de una condición de exclusión incluyente, independientemente de las formas o maneras en las que se presenta y materializa" (15, traducción propia). Sin embargo, al dejar de lado la importancia de este contexto espacial, temporal y social, las inferencias teóricas del libro son debatibles.

El subtítulo indica que el lector se encontrará con un análisis sobre "el poder, la historia y el Estado colombiano en la amazonia colombiana". Pero el libro se basa únicamente en el estudio riguroso del camino que va de Pasto a Mocoa a partir del 
cual, al menos en los capítulos teóricos, pretende hacer generalizaciones sobre toda la región amazónica. Dichas generalizaciones son dudosas puesto que el comportamiento del Estado colombiano en Putumayo no es la regla: no en todos los departamentos de la región la condición de frontera ha sido construida mediante el impulso de vías y mucho menos de tal magnitud. El autor extrae conclusiones teóricas a partir de los conflictos surgidos en torno a la vía, sin mencionar que actualmente tres de los seis departamentos de la región amazónica (Guainía, Amazonas y Vaupés) no están conectados con la región andina por medio de una carretera. La situación de Putumayo es diferente a la de otros departamentos amazónicos que, como Caquetá, también están conectados por carretera. En Caquetá el papel de los capuchinos fue mucho menos importante que en Putumayo y, en la actualidad, el camino que conecta a Caquetá con la región andina no ha sido una prioridad identificada por la IIRSA. La región amazónica es diversa y en materia de megaproyectos de infraestructura, Putumayo es una excepción.

Además de diversa, la región es cambiante. No obstante, el libro concluye que el proyecto civilizatorio del Estado en la región amazónica, ha permanecido "inmutable" (240-241) a pesar de algunos cambios menores. Simón Uribe dice muy poco sobre lo ocurrido entre los dos momentos históricos estudiados, es decir, entre la concepción y construcción de la vía de finales del siglo XIX e inicios del XX y las dinámicas contemporáneas asociadas a la construcción de la variante. Con ello no solo deja de lado un sinnúmero de transformaciones -por ejemplo, la colonización agraria, la extracción de petróleo, el fin de la misión capuchina, la llegada de la coca-, sino que desaprovecha el potencial teórico ligado a la historia de la región. Ahora bien, incluso si el lector fuese persuadido por el carácter "inmutable" de la condición de frontera, es necesario analizar por qué, a pesar del paso del tiempo, no hay cambios significativos. ¿Cuáles son los mecanismos concretos por medio de los cuales la condición de frontera se ha reproducido con tanto éxito por más de un siglo?

Estas críticas sobre la diversidad y la historia regional por supuesto son menores ante la magnitud de la contribución. El libro es sin duda fundamental para comprender el papel del Estado y la violencia asociada con la exclusión incluyente de la región amazónica. Gracias al rigor del trabajo de archivo, a la profundidad del trabajo etnográfico, a la agudeza de las reflexiones teóricas y a la calidad de la escritura es muy probable que este libro se convierta en un nuevo hito en los estudios críticos sobre el Estado en Colombia desde uno de sus márgenes. 


\section{Referencias}

Bonilla, Víctor-Daniel (1968). Siervos de Dios y amos de indios. El Estado y la misión capuchina en el Putumayo. Bogotá: Tercer Mundo.

Cancimance-López, Andrés (2017). Echar raíces en medio del conflicto armado: resistencias cotidianas de colonos en Putumayo. Bogotá: Universidad Nacional de Colombia/Biblioteca Pública Luis Carlos Galán Sarmiento/A la Orilla del Río.

Centro Nacional de Memoria Histórica (2011). La masacre de El Tigre. Un silencio que encontró su voz. Bogotá: Imprenta Nacional de Colombia.

Centro Nacional de Memoria Histórica (2012). El Placer. Mujeres, coca y guerra en el bajo Putumayo. Bogotá: Imprenta Nacional de Colombia.

Centro Nacional de Memoria Histórica (2015). Petróleo, coca, despojo territorial y organizacion social en Putumayo. Bogotá: CNMH.

Ramírez, María-Clemencia (2001). Entre el Estado y la guerrilla: identidad y ciudadanía en el movimiento de los campesinos cocaleros del Putumayo. Bogotá: Instituto Colombiano de Antropología e Historia.

Serje, Margarita (2011). El revés de la nación. Territorios salvajes, fronteras y tierras de nadie. Bogotá: Uniandes.

Torres-Bustamante, María-Clara (2011). Estado y coca en la frontera colombiana. El caso del Putumayo. Bogotá: CINEP/ODECOFI. 